\title{
Availability of Long Acting Reversible Contraceptives for Adolescents in Urban vs Rural West Virginia Counties
}

Brooke Andrews, MD, MPH ${ }^{1}$, Cameron Ross, MD², Jennie Yoost, MD, MSc $^{2}$

ABSTRACT

The study objective was to evaluate long acting reversible contraceptive (LARC) method availability and access for adolescents in rural and urban counties in West Virginia (WV). A cross-sectional survey of Title X family planning providers throughout WV was conducted from January 2016 to July 2017. This survey was sent to 226 family planning providers in WV to assess patterns of LARC availability. The survey assessed provider training level, LARC services provided and frequency, clinical practice, referral patterns, and comfort level providing adolescent LARC services. Survey results were analyzed by providers' rural vs urban status, based on US census county codes. Survey responses yielded 127 total responders, 65 (51.2\%) were urban, and the remaining 62 (48.8\%), were rural. Urban providers had a larger representation of medical doctors, while rural providers were primarily nurse practitioners $(p<0.001)$. Intrauterine devices (IUD) had lower availability with rural providers $(p<0.006)$. Years of experience doing IUD placement $(p<0.010)$, frequency of placing implants $(p<0.010)$, and frequency placing implants in teenagers $(p<0.012)$ were significantly less in rural providers.
Author affiliations are listed at the end of this article.

Correspondence to: Jennie Yoost, MD, MSc Marshall Unviersity Joan C. Edwards School of Medicine yoost@marshall.edu

\section{KEYWORDS}

adolescent pregnancy, long active reversible contraceptives, rural, intrauterine devices (IUD), subdermal contraceptive implant

\section{INTRODUCTION}

Nearly half of the 6.7 million pregnancies reported in the United States each year are unintended, and this rate is even higher among $15-19$ year old women (82\%). ${ }^{1}$ West Virginia ranks 43 rd out of the 50 states in teen birth rate, with a rate of $29 .{ }^{3}$ births per 1000 girls age 15-19 in 2016. This rate is down 8\% from 2015, and WV ranks 24th nationally in positive change in teen birth rate. ${ }^{2}$ Despite this decrease, disparities exist between pregnancy rates in urban and rural counties. $^{3}$

The effectiveness of long-acting reversible contraceptives (LARCs), which include both intrauterine devices (IUDs) and subdermal implants, has been illustrated in many studies. Women who are 21 years of age and younger who use the pill, patch, or ring have almost twice the risk of unintended pregnancy as older women using the same methods. ${ }^{4}$ The American College of Obstetricians and Gynecologists recommends LARCs as first-line methods for contraception in the adolescent age group. ${ }^{5}$ Title $\mathrm{X}$ is the only federal grant program dedicated solely to providing individuals with comprehensive family planning and related preventive health services. Title $X$ or family planning clinics are therefore a valuable resource for women and adolescents seeking contraceptive care including LARCs. IUDs and implants, however, require training for provision. Depending on trained provider availability, access to these LARC methods may be limited in certain settings, specifically rural areas.

Previous studies have assessed IUD and subdermal implant access in rural areas. One study in a nationwide sample evaluated on-site availability of these methods and found that two-thirds of Title $X$ family planning clinics offered IUDs, but only $36 \%$ offered on-site implants. Researchers concluded 
that smaller clinics and more rural areas may have fewer choices in contraception. ${ }^{6}$ Another study found that Title $X$ resources were associated with an increase use of LARC methods compared to nonTitle $X$ clinics when controlling for clinic size and urban/rural location. ${ }^{7}$ While these studies may show the advantages that Title $X$ resources can achieve with LARC availability, neither evaluated family planning providers training, experience, and comfort levels with offering LARC services specifically to an adolescent population.

Provider attitudes and training can affect the use of LARCs in rural areas. A lack of trained providers along with providers that may be hesitant to perform these services in specific populations can also lead to underuse of these methods. One study evaluated misperceptions and practice patterns among Title $X$ providers in urban and rural areas in Texas. Providers in rural areas were less likely to recognize benefits of LARC contraceptives and were more cautious in recommending LARCs to adolescents. ${ }^{8}$ This study did not specifically survey practice patterns of providers trained in LARC insertion.

The goal of the current study was to evaluate practice patterns of providers and availability of LARC services for adolescents in individual counties of WV, specifically those designated "rural." Urban and rural family planning providers were compared in regard to LARC services offered, experience with LARC, and frequency and comfort of LARC use in adolescents.

\section{MATERIALS AND METHODS}

This is a cross-sectional survey study evaluating availability LARCs in urban and rural counties in WV. A list of Title $X$ family planning clinics and providers were obtained from the WV Department of Health and Human Resources. Family planning providers contacted included various backgrounds in training (MD, NP, CNM and RN). The family planning providers were initially contacted by email inviting them to participate in the survey study. Two months later, the survey was then sent through the mail to providers that did not initially respond to the online survey request. The emailed survey was conducted through the use of an online survey tool, and the printed copy of the survey was mailed with a prepaid return envelope. Providers were given the incentive of a $\$ 20$ gift card, which was mailed to providers after completing the online survey. This incentive was included along with the mailed survey. Data was collected between June 2016 and January of 2017.

The survey assessed provider age, level of training, frequency of IUD insertion in adults and among adolescents, frequency of implant insertion in adults and adolescents, and amount of time certified to provide LARC services. The survey also assessed clinical practice, referral patterns, and the comfort level of providing these services to adolescents assessed by a series of clinical vignettes. STD screening practices were also assessed with IUD use.

WV counties were assigned rural and urban designations from the Rural-Urban Commuting Area Codes. This is a Census based classification that utilizes the Bureau of Census Urbanized Area and Urban Cluster definitions to characterize the nation's Census tracts regarding their rural and urban status. Urban areas (categories 1-3) include areas with populations $>50,000$ people, Large Rural (categories 4-6) include areas with populations of 10,000-50,000 people, Small Rural (categories 7-9) 2,500 - 9,999, and Isolated Rural/Frontier (category 10) have less than 2,500 people. Counties were dichotomized into urban or rural classification using the categories 1-3 for urban designation and 4 or greater as rural. Urban and rural counties were compared by number of LARC providers per county, and differences in responses to surveyed questions on LARC practice.

SPSS v24 was used for analysis of descriptive statistics and use of Pearson's Chi-square test for assessing the categorical variables between rural and urban providers. SPSS was also used to conduct an analysis of variance (ANOVA) assessing for differences in means of continuous variables between groups. A consent statement was included at the start of the online and mailed survey, and all information recorded from the survey was deidentified. Institutional review board approval was obtained prior to study initiation. 


\section{RESULTS}

A total of 226 family planning providers were contacted through a list of clinics obtained from the WV Department of Health and Human Resources. Survey responses yielded 127 (56\%) total responders, 52 (40.9\%) via online and a remaining $75(59.1 \%)$ via mail return. Of the responders, 65 (51.2\%) were classified as urban, and the remaining $62(48.8 \%)$ were classified as rural. Table 1 shows differences in demographics and practice patterns between the urban and rural providers. Urban and rural healthcare providers did not differ significantly in age $(p=0.291)$, or years of practice $(p=0.154)$. There was a significant difference $(p<0.001)$ between providers and their level of training; MDs were the largest represented group in urban settings (33.8\%); NPs were in rural settings (35.5\%). Providers were not significantly different in the number of days per week that they worked; for all providers the average was $4.40 \pm 1.12$ days. The number of counties that healthcare providers practiced within was significantly different between rural and urban providers. Urban providers practiced on average in $1.23 \pm 0.55$ counties, compared to $1.73 \pm 1.16$ for rural providers $(p=<0.002)$.

Barriers to LARC access including insurance coverage, confidentiality, provider comfort level in performing the procedure, transportation, and safety concerns are demonstrated in Table 2. Safety concerns for IUD placement was the only barrier found to be significantly different between rural and urban healthcare providers $(p<0.007)$. Of healthcare providers that offer IUDs, rural providers responded more frequently $(41.5 \%)$ that safety concerns with IUD placement was 'Somewhat Major' barrier to access, while urban healthcare providers responded most frequently that it was a 'Minor' barrier to access (52.5\%).

\begin{tabular}{|l|l|l|l|l|}
\hline & & Rural (N, \%) & Urban (N, \%) & p value \\
\hline Age & $20-29$ & $4(6.5 \%)$ & $1(1.6 \%)$ & 0.291 \\
& $30-39$ & $21(33.9 \%)$ & $20(31.3 \%)$ & \\
& $40-49$ & $21(33.9 \%)$ & $15(23.4 \%)$ & \\
& $50-59$ & $9(14.5 \%)$ & $15(23.4 \%)$ & \\
& $60-69$ & $5(8.1 \%)$ & $10(15.6 \%)$ & \\
& $70-79$ & $2(3.2 \%)$ & $3(4.7 \%)$ & \\
& Total & 62 & 64 & \\
\hline Training & RN & $14(22.6 \%)$ & $5(7.7 \%)$ & \\
& NP & $22(35.5 \%)$ & $21(32.3 \%)$ & \\
& PA & $11(17.7 \%)$ & $4(6.2 \%)$ & \\
& MD & $6(9.7 \%)$ & $22(33.8 \%)$ & \\
& DO & $5(8.1 \%)$ & $5(7.7 \%)$ & \\
& CNM & $0(0 \%)$ & $7(10.8 \%)$ & \\
& Other & $4(6.5 \%)$ & $1(1.5 \%)$ & \\
\hline Years of & Total & 62 & 65 & \\
Practice & & & & \\
& $<5$ yrs & $22(35.5 \%)$ & $10(15.4 \%)$ & 0.154 \\
& $5-10$ yrs & $14(22.6 \%)$ & $23(35.4 \%)$ & \\
& $11-20$ yrs & $8(12.9 \%)$ & $9(13.8 \%)$ & \\
& $21-30$ yrs & $14(22.6 \%)$ & $15(23.1 \%)$ & \\
& $31-40$ yrs & $2(3.2 \%)$ & $4(6.2 \%)$ & \\
& $>40$ yrs & $2(3.2 \%)$ & $4(6.2 \%)$ & \\
& Total & 62 & 65 & \\
\hline
\end{tabular}

TABLE 1: Demographics of healthcare providers including age, training, and years of practice. 


\begin{tabular}{|c|c|c|c|c|}
\hline & & Rural (N, \%) & Urban (N, \%) & P value \\
\hline $\begin{array}{l}\text { Insurance } \\
\text { Coverage }\end{array}$ & $\begin{array}{l}\text { Very minor } \\
\text { Minor } \\
\text { Somewhat Major } \\
\text { Major } \\
\text { Total }\end{array}$ & $\begin{array}{l}20(38.5 \%) \\
15(28.8 \%) \\
6(11.5 \%) \\
11(21.2 \%) \\
52\end{array}$ & $\begin{array}{l}29(46.8 \%) \\
17(27.4 \%) \\
10(16.1 \%) \\
6(9.7 \%) \\
62\end{array}$ & 0.334 \\
\hline $\begin{array}{l}\text { Confidentiality } \\
\text { issues }\end{array}$ & $\begin{array}{l}\text { Very minor } \\
\text { Minor } \\
\text { Somewhat Major } \\
\text { Major } \\
\text { Total }\end{array}$ & $\begin{array}{l}25(47.2 \%) \\
15(28.3 \%) \\
10(18.9 \%) \\
3(5.7 \%) \\
53\end{array}$ & $\begin{array}{l}30(49.2 \%) \\
18(29.5 \%) \\
12(19.7 \%) \\
1(1.6 \%) \\
61\end{array}$ & 0.716 \\
\hline $\begin{array}{l}\text { Provider } \\
\text { comfort level in } \\
\text { performing the } \\
\text { procedure }\end{array}$ & $\begin{array}{l}\text { Very minor } \\
\text { Minor } \\
\text { Somewhat Major } \\
\text { Major } \\
\text { Total }\end{array}$ & $\begin{array}{l}17(33.3 \%) \\
11(21.6 \%) \\
11(21.6 \%) \\
12(23.5 \%) \\
51\end{array}$ & $\begin{array}{l}23(37.7 \%) \\
21(34.4 \%) \\
10(16.4 \%) \\
7(11.5 \%) \\
61\end{array}$ & 0.209 \\
\hline Transportation & $\begin{array}{l}\text { Very minor } \\
\text { Minor } \\
\text { Somewhat Major } \\
\text { Major } \\
\text { Total }\end{array}$ & $\begin{array}{l}14(26.4 \%) \\
16(30.2 \%) \\
18(34.0 \%) \\
5(9.4 \%) \\
53\end{array}$ & $\begin{array}{l}14(23.0 \%) \\
24(39.3 \%) \\
17(27.9 \%) \\
6(9.8 \%) \\
61\end{array}$ & 0.762 \\
\hline Safety concerns & $\begin{array}{l}\text { Very minor } \\
\text { Minor } \\
\text { Somewhat Major } \\
\text { Major } \\
\text { Total }\end{array}$ & $\begin{array}{l}16(30.2 \%) \\
14(26.4 \%) \\
22(41.5 \%) \\
1(1.9 \%) \\
53\end{array}$ & $\begin{array}{l}16(26.2 \%) \\
32(52.5 \%) \\
10(16.4 \%) \\
3(4.9 \%) \\
61\end{array}$ & 0.007 \\
\hline Having an exam & $\begin{array}{l}\text { Very minor } \\
\text { Minor } \\
\text { Somewhat Major } \\
\text { Major } \\
\text { Total }\end{array}$ & $\begin{array}{l}14(26.4 \%) \\
17(32.1 \%) \\
19(35.8 \%) \\
3(5.7 \%) \\
53\end{array}$ & $\begin{array}{l}19(31.1 \%) \\
23(37.7 \%) \\
14(23.0 \%) \\
5(8.2 \%) \\
61\end{array}$ & 0.500 \\
\hline
\end{tabular}

TABLE 2: Distribution of responses of healthcare providers based on their rural vs urban location on the severity of perceived barriers to patient IUD access.

Providers were surveyed as to the various types of contraceptives offered within the family planning clinic where they practiced. This included the oral contraceptive pill (OCP), patch (Ortho Evra ${ }^{\circledR}$ ), ring (NuvaRing ${ }^{\circledast}$ ), depo medroxyprogesterone acetate (DMPA), emergency contraception, subdermal implant (Nexplanon ${ }^{\circledast}$ ), levonorgestrel intrauterine devices (Mirena ${ }^{\circledR}$, Skyla ${ }^{\circledR}$, Liletta ${ }^{\circledR}$ ), and the copper IUD (Paragard $\left.{ }^{\oplus}\right)$. All of the IUD contraceptive options, Mirena, Skyla, and Paragard, (with the exception of Liletta, which had a very low availability grossly $(10.2 \%))$, were offered significantly less often with rural healthcare clinics than they were with urban clinics $(59.7 \%$ vs $81.5 \%, p<0.007 ; 21 \%$ vs $52.3 \%$, $\mathrm{p}<0.001$; and $45.2 \%$ vs $73.8 \% \mathrm{p}<0.001$, respectively). There were no significant differences in availability of OCPs, patch, ring, DMPA, EC, or subdermal implant between rural and urban clinics.

LARC procedures were compared among both urban and rural providers after excluding RNs who in general are not trained in this procedure. Among urban providers (MD, DO, NP, PA, CNM), 70\% performed IUD placements, while only $50 \%$ of these rural providers performed this service $(p<0.006)$. IUD availability is demonstrated in Table 3 among urban and rural providers. Years of experience placing IUDs were found to be significantly less $(p<0.010)$ in rural 


\begin{tabular}{|c|c|c|c|c|}
\hline & & Rural N (\%) & Urban N (\%) & P value \\
\hline $\begin{array}{l}\text { Years doing } \\
\text { IUD }\end{array}$ & $\begin{array}{l}<5 \mathrm{yrs} \\
5-10 \mathrm{yrs} \\
11-15 \mathrm{yrs} \\
16-20 \mathrm{yrs} \\
21-25 \mathrm{yrs} \\
>25 \mathrm{yrs} \\
\text { Total }\end{array}$ & $\begin{array}{l}13(54.2 \%) \\
6(25 \%) \\
3(12.5 \%) \\
0(0 \%) \\
0(0 \%) \\
2(8 / 3 \%) \\
24\end{array}$ & $\begin{array}{l}6(14.3 \%) \\
16(38.1 \%) \\
4(9.5 \%) \\
4(9.5 \%) \\
4(9.5 \%) \\
8(19 \%) \\
42 \\
\end{array}$ & 0.010 \\
\hline $\begin{array}{l}\text { Frequency of } \\
\text { IUD }\end{array}$ & $\begin{array}{l}\text { Daily } \\
\text { At least once weekly } \\
\text { At least twice monthly } \\
\text { Once monthly } \\
\text { A few times per year } \\
\text { Less than once yearly } \\
\text { Total }\end{array}$ & $\begin{array}{l}2(8.3 \%) \\
5(20.8 \%) \\
6(25 \%) \\
5(20.8 \%) \\
4(16.7 \%) \\
2(8 / 3 \%) \\
24 \\
\end{array}$ & $\begin{array}{l}8(19 \%) \\
19(45.2 \%) \\
5(11.9 \%) \\
5(11.9 \%) \\
4(9.5 \%) \\
1(2.4 \%) \\
42 \\
\end{array}$ & 0.164 \\
\hline $\begin{array}{l}\text { Frequency of } \\
\text { teen IUD }\end{array}$ & $\begin{array}{l}\text { Daily } \\
\text { At least once weekly } \\
\text { At least twice monthly } \\
\text { Once monthly } \\
\text { A few times per year } \\
\text { Less than once yearly } \\
\text { Total }\end{array}$ & $\begin{array}{l}0(0 \%) \\
1(4.2 \%) \\
5(20.8 \%) \\
1(4.2 \%) \\
12(50 \%) \\
5(20.8 \%) \\
24 \\
\end{array}$ & $\begin{array}{l}1(2.4 \%) \\
4(9.8 \%) \\
8(19.5 \%) \\
5(12.2 \%) \\
17(41.5 \%) \\
6(14.6 \%) \\
41 \\
\end{array}$ & 0.721 \\
\hline $\begin{array}{l}\text { Years doing } \\
\text { Implant }\end{array}$ & $\begin{array}{l}<5 \mathrm{yrs} \\
5-10 \mathrm{yrs} \\
11-15 \mathrm{yrs} \\
16-20 \mathrm{yrs} \\
21-25 \mathrm{yrs} \\
>25 \mathrm{yrs} \\
\text { Total } \\
\end{array}$ & $\begin{array}{l}28(71.8 \%) \\
6(15.4 \%) \\
2(5.1 \%) \\
1(2.6 \%) \\
1(2.6 \%) \\
1(2.6 \%) \\
39 \\
\end{array}$ & $\begin{array}{l}18(40.9 \%) \\
19(43.2 \%) \\
3(6.8 \%) \\
1(2.3 \%) \\
3(6.8 \%) \\
0(0 \%) \\
44 \\
\end{array}$ & 0.054 \\
\hline $\begin{array}{l}\text { Frequency of } \\
\text { Implant }\end{array}$ & $\begin{array}{l}\text { Daily } \\
\text { At least once weekly } \\
\text { At least twice monthly } \\
\text { Once monthly } \\
\text { A few times per year } \\
\text { Less than once yearly } \\
\text { Total }\end{array}$ & $\begin{array}{l}0(0 \%) \\
10(25 \%) \\
11(27.5 \%) \\
8(20 \%) \\
7(27.5 \%) \\
4(10 \%) \\
40\end{array}$ & $\begin{array}{l}7(15.9 \%) \\
17(38.6 \%) \\
10(22.7 \%) \\
3(6.8 \%) \\
7(15.9 \%) \\
0(0 \%) \\
44\end{array}$ & 0.010 \\
\hline $\begin{array}{l}\text { Frequency of } \\
\text { teen implant }\end{array}$ & $\begin{array}{l}\text { Daily } \\
\text { At least once weekly } \\
\text { At least twice monthly } \\
\text { Once monthly } \\
\text { A few times per year } \\
\text { Less than once yearly } \\
\text { Total }\end{array}$ & $\begin{array}{l}0(0 \%) \\
7(17.5 \%) \\
4(10 \%) \\
8(20 \%) \\
15(37.5 \%) \\
6(15 \%) \\
40 \\
\end{array}$ & $\begin{array}{l}5(11.4 \%) \\
13(29.5 \%) \\
11(25 \%) \\
3(6.8 \%) \\
9(20.5 \%) \\
3(6.8 \%) \\
44 \\
\end{array}$ & 0.012 \\
\hline
\end{tabular}

TABLE 3: Frequency of IUD and implant provision among urban and rural providers.

providers ( $54.2 \%$ have $<5$ years experience) than in urban providers (38.1\% have $5-10$ years experience). Providers did not differ significantly in frequency of placing IUDs, or frequency of placing IUDs in teenagers in rural or urban settings.

STD screening protocols during IUD placement were found to be significantly different between urban and rural providers. The majority of both rural and urban providers reported they would do the IUD insertions at the time of gonorrhea and chlamydia screening (54.2\%, and $81.8 \%$, respectively), however, a substantial proportion of the rural providers required screening to be resulted prior to insertion ( $37.5 \%$ vs $9 \%$ of urban providers, $p=0.032$ ). Examples of the clinical vignettes use to assess provider comfort with LARC insertion are shown in Table 4. No differences were found between urban and rural healthcare providers in their comfort level with the various clinical vignettes presented with different ages and parity.

Implants were performed by $81.2 \%$ of rural providers and $73.3 \%$ of urban providers $(p=0.33)$. Subdermal implant accessibility is demonstrated in Table 3 among urban and rural providers. For both rural and urban providers that did not perform implant insertion, referral is most commonly made to another provider within their facility. For providers that offer implants, their amount of experience performing the procedure did not differ based on urban or rural setting. However, frequency of placing subdural implants $(p<0.010)$ and frequency placing subdermal implants in teenagers $(p<0.012)$ was significantly less in rural providers than in urban providers. No differences were found between urban 


\begin{tabular}{|c|c|c|c|c|}
\hline Vignette & & Rural N (\%) & Urban N (\%) & $\underline{\text { P value }}$ \\
\hline $\begin{array}{l}\text { An 18-year-old } \\
\text { patient with prior } \\
\text { pregnancy and } \\
\text { delivery desires } \\
\text { an intrauterine } \\
\text { device insertion. }\end{array}$ & $\begin{array}{l}\text { Very uncomfortable } \\
\text { Somewhat Uncomfortable } \\
\text { Comfortable } \\
\text { Very Comfortable } \\
\text { Total }\end{array}$ & $\begin{array}{l}5(22.7 \%) \\
0(0 \%) \\
4(18.2 \%) \\
13(59.1 \%) \\
22\end{array}$ & $\begin{array}{l}5(11.6 \%) \\
0(0 \%) \\
2(4.7 \%) \\
36(83.7 \%) \\
43\end{array}$ & 0.073 \\
\hline $\begin{array}{l}\text { An 18-year-old } \\
\text { patient who has } \\
\text { never been } \\
\text { pregnant desires } \\
\text { an intrauterine } \\
\text { device insertion. }\end{array}$ & $\begin{array}{l}\text { Very uncomfortable } \\
\text { Somewhat Uncomfortable } \\
\text { Comfortable } \\
\text { Very Comfortable } \\
\text { Total }\end{array}$ & $\begin{array}{l}2(9.1 \%) \\
5(22.7 \%) \\
6(27.3 \%) \\
9(40.9 \%) \\
22\end{array}$ & $\begin{array}{l}3(7.0 \%) \\
3(7.0 \%) \\
9(20.9 \%) \\
26(65.1 \%) \\
43\end{array}$ & 0.189 \\
\hline $\begin{array}{l}\text { A 16-year-old } \\
\text { patient who has } \\
\text { never been } \\
\text { pregnant desires } \\
\text { an intrauterine } \\
\text { device insertion. }\end{array}$ & $\begin{array}{l}\text { Very uncomfortable } \\
\text { Somewhat Uncomfortable } \\
\text { Comfortable } \\
\text { Very Comfortable } \\
\text { Total }\end{array}$ & $\begin{array}{l}2(9.1 \%) \\
6(27.3 \%) \\
5(22.7 \%) \\
9(40.9 \%) \\
22\end{array}$ & $\begin{array}{l}4(9.5 \%) \\
4(9.5 \%) \\
12(28.6 \%) \\
22(52.4 \%) \\
42\end{array}$ & 0.322 \\
\hline $\begin{array}{l}\text { A 13-year-old } \\
\text { patient who has } \\
\text { never been } \\
\text { pregnant desires } \\
\text { an intrauterine } \\
\text { device insertion. }\end{array}$ & $\begin{array}{l}\text { Very uncomfortable } \\
\text { Somewhat Uncomfortable } \\
\text { Comfortable } \\
\text { Very Comfortable } \\
\text { Total }\end{array}$ & $\begin{array}{l}7(33.3 \%) \\
8(38.1 \%) \\
2(9.5 \%) \\
4(19.0 \%) \\
21\end{array}$ & $\begin{array}{l}10(23.3 \%) \\
19(44.2 \%) \\
8(18.6 \%) \\
6(14.0 \%) \\
43\end{array}$ & 0.650 \\
\hline
\end{tabular}

TABLE 4: Healthcare providers' responses on their level of comfort with the listed vignettes for intrauterine device placement, separated by their rural vs urban classification.

and rural healthcare providers in their comfort level with subdermal implant placement among the clinical vignettes (data not shown).

\section{DISCUSSION}

This study supports prior studies in other states demonstrating that women in rural areas may have fewer contraceptive options available. ${ }^{6}$ However, the current study evaluated provider practice patterns with LARCs specific to an adolescent population, in whom barriers to seeking contraception are likely amplified. This study demonstrated that fewer family planning clinics offered IUDs in rural counties in West Virginia. Rural providers had less experience with IUD insertion, had more safety concerns with IUDs in adolescents, and were more likely to want STD testing resulted prior to IUD placement. Safety concerns may be a reflection of level of training, frequency of placement, or simply lack of demand for this contraceptive method among a rural adolescent population. Despite these barriers, among providers that did supply IUDs, the frequency of IUD placement among adolescents was not significantly different between rural and urban counties.

With regards to implants, experience did not differ between rural and urban providers, however, frequency of use in adolescents was higher in urban settings. The frequency of implant placement is likely a result of overall patient volume due to population density in an urban setting.

Providers completing the survey nearly equally represented rural and urban practice settings. Survey methods of data collection strengthened the study by making it cost effective and allowed the surveillance of a large number of healthcare providers in the state of West Virginia, increasing the potential generalizability. However, the surveys contained categorical answer options and did not accommodate alternative answers. This poses a validity weakness of the study in its ability to 
completely distinguish all perspectives. Placing all rural areas (large rural, small rural, and isolated) into one group is also limiting as these areas may have different resources. The demand for LARC services within each area was also not assessed and could obviously impact frequencies and availability.

Accessibility to LARC services is also affected by factors outside of the provider. In a recent nationwide analysis of publicly funded family planning facilities, youth friendly practices and access to LARCs were analyzed.9 Accessibility to younger clients was achieved by not requiring scheduled appointments, having flexible hours, and providing outreach and education to younger patients. These youth friendly sites had increased rates of LARC provision among younger clients.9 Title $X$ has a strong commitment to the provision of contraception to adolescents, and Title $X$ guidelines stress the importance of adolescent confidentiality and provision of youth friendly services. However, some of these youth friendly services (flexible hours, walk in appointments, availability by public transport) may be inherently difficult in more rural locations.

This study highlights possible barriers to provision of LARC services to adolescents in rural areas, which can be extrapolated beyond West Virginia to demographically similar regions. Title $X$ clinics remain a valuable source of contraceptive provision for women and adolescents. Further studies could be aimed at developing innovative strategies and resources for training providers in rural areas and expanding youth friendly services.

\section{AUTHOR AFFILIATIONS}

1. University of Kentucky, Lexington, Kentucky

2. Marshall University Joan C. Edwards School of Medicine, Huntington, West Virginia

\section{REFERENCES}

1. Hamilton BE, Martin JA, Osterman MJ. Births: Preliminary Data for 2015. National vital statistics reports: from the Centers for Disease Control and Prevention, National Center for Health Statistics, National Vital Statistics System 2016;65(3):1-15.
2. The Power To Decide. Secondary The Power To Decide. https://powertodecide.org/what-we-do/ information/national-state-data/west-virginia.

3. Kids Count Data Center. Secondary Kids Count Data Center The Annie E Casey Foundation. http://datacenter.kidscount.org.

4. Winner B, Peipert JF, Zhao Q, et al. Effectiveness of long-acting reversible contraception. The New England Journal of Medicine 2012;366(21):19982007.

5. Committee on adolescent health care longacting reversible contraception working group. The American College of Obstetricians and Gynecologists. Committee opinion no. 539: adolescents and long-acting reversible contraception: implants and intrauterine devices. Obstetrics and gynecology 2012;120(4):983-8 .

6. Beeson T, Wood S, Bruen B, Goldberg DG, Mead $\mathrm{H}$, Rosenbaum $\mathrm{S}$. Accessibility of long-acting reversible contraceptives (LARCs) in federally qualified health centers (FQHCs). Contraception 2014;89(2):91-6.

7. Park HY, Rodriguez MI, Hulett D, Darney PD, Thiel de Bocanegra $\mathrm{H}$. Long-acting reversible contraception method use among Title $X$ providers and non-Title $X$ providers in California. Contraception 2012;86(5):557-61.

8. Vaaler ML, Kalanges LK, Fonseca VP, Castrucci BC. Urban-rural differences in attitudes and practices toward long-acting reversible contraceptives among family planning providers in Texas. Women's health issues: official publication of the Jacobs Institute of Women's Health 2012;22(2):e157-62.

9. Kavanaugh ML, Jerman J, Ethier K, Moskosky S. Meeting the contraceptive needs of teens and young adults: youth-friendly and long-acting reversible contraceptive services in U.S. family planning facilities. The Journal of Adolescent Health : official publication of the Society for Adolescent Medicine 2013;52(3):284-92. 